\title{
Research Directions in Interior Architecture in the Higher Education in Thailand (1997-2016)
}

\author{
Thirayu Jumsai na Ayudhya ${ }^{1}$ \\ ${ }^{1}$ King Mongkut's Institute of Technology Ladkrabang, Bangkok, 10520, Thailand \\ Correspondence: Thirayu Jumsai na Ayudhya. E-mail: thijumsai@gmail.com
}

Received: April 27, 2017

Accepted: June 8, 2017 Online Published: July 25, 2017

doi:10.5539/ass.v13n8p60

URL: https://doi.org/10.5539/ass.v13n8p66

\begin{abstract}
This research aims to explore research directions in interior architecture in the higher education in Thailand within the past two decades (1997-2016). This research is a part of the quinquennial curriculum renewal process of the master degree of interior architecture programme, Department of Interior Architecture, King Mongkut's Institute of Technology Ladkrabang (KMITL). The systematic literature review was conducted to track back on theses in interior architecture in the higher education in Thailand. The query focused on master degree theses published from 1997 to 2016 within ThaiLIS-Thai Library Integrated System (TTLIS) in which research, theses, and dissertations of all universities in Thailand were systematically collected. The keyword 'interior architecture' was used to search for thesis documents in TTLIS with specifically refined results on master degree theses in all universities in Thailand. One hundred and ninety-six theses were found in the search. This research comprises two stages. In the first stage, all one hundred and ninety-six theses were systematically reviewed and categorized into different types of research. It was found that there was no predictive research type and no novel theoretical framework generated among studied theses. In second stage, semi-structure interview was adopted to explore details of participants' experiences of doing their theses; inspirations, background ideas, supports, and obstacles. A lack of generating new theoretical frameworks in interior architecture in the higher education in Thailand has weaken the progression of research in this discipline. Developing a novel theoretical framework in interior architecture in the higher education in Thailand is recommended.
\end{abstract}

Keywords: Interior Architecture research, research direction, the higher education curriculum development

\section{Introduction}

The important role of curriculum is to provide a framework for relevant educational courses (Khan \& Law, 2015). The meaning of curriculum can be perceived in different perspectives by teachers and students (Lattuca \& Stark, 2009). Curriculum development is a set of courses or entire program within a subject specialty or discipline (Connecticut, 2006) It is vital to regularly revise curriculum to make the content or the subject matter of the curriculum up to date and conform with current situations (Nielsen, Ieromonachou, Lin, \& White, 2015; Kawser, 2014). The Office of the Higher Education Commission (OHEC) is responsible for monitoring the higher education standard of all universities in Thailand. In 2009, OHEC announced the regulation for Thai higher education degree, master and doctoral degree (Office of the Higher Education Commission, 2009). The OHEC's regulation issued in 2009 mandated all Thai's universities under the jurisdiction of OHEC to renew curriculum quinquennially. Thailand's higher education level in interior architecture was founded in 1993. Nowadays, in Thailand there are four universities providing higher degree in interior architecture. The Department of Interior Architecture, Faculty of Architecture at King Mongkut's Institute of Technology Ladkrabang (KMITL), have been administering a Master course of interior architecture since 1993. The curriculum for this course has been continuously renewed. To comply with OHEC regulation issued in 2009, the Department of Interior Architecture, Faculty of Architecture, KMITL was required to renew the current curriculum, which has been used for nearly five years since 2012. In December 2016, the Department of Interior Architecture set up the research project to gather information in preparation for the curriculum renewal in the mid of 2017, and this paper is a part of the project. There are several conceptual models used to develop curriculum in the higher education, for example; the Addie's model, an integrative approach model, and O'Neill's curriculum design process. Although among those models the process of developing curriculum is different in details, the mutual key processes those models is to track back on the learning outcome. 
Understanding of research directions in the past contributes to the effectiveness of a curriculum renewal and a curriculum development (Nielsen, Ieromonachou, Lin, \& White, 2015). So, a reliable tracking back on the previous research was required for curriculum renewal. In the first stage, a systematic literature review on previous theses documents provided the overview of research directions in such discipline (Cooper, Hedges, \& Valentine, 2009). A systematic literature review comprises five major steps, 1) framing the question, 2) identifying relevant work, 3) assessing the quality of studies, 4) summarizing the evidence, and 5) interpreting the findings. These steps distinguish a systematic review from a traditional and commentaries review (Khan, Kunz, Kleijnen, \& Antes, 2003; Centre for Reviews and Dissemination, 2009). In addition, in the second stage inquiring participants of studied theses with semi-structure interview was adopted to explore more about experiences; background ideas, inspirations, and attitudes, during the time participants were conducting master degree research. This research aims to understand research directions by tracking back on published thesis documents in interior architecture in the higher education level in Thailand in recent 20 years. The main database used for the systematic literature review was ThaiLIS-Thai Library Integrated System (TTLIS) where all research and theses from all universities in the higher education level in Thailand were systematically collected. Department of Interior Architecture, KMITL will take the results of this research as a resource for KMITL curriculum renewal in the mid of 2017.

\section{Method}

The study of research directions requires qualitative approach to profoundly analyse research contents. This can provide exploratory outcome; an understanding of research directions in a specific discipline. In addition, understanding of researchers' background ideas, experiences, and attitudes can help us to understand research directions (Paulhus \& Vazire, 2007). This research comprises two main stages. Firstly, in the first stage this research began with systematic literature review through previous relevant thesis documents in interior architecture in the higher education in Thailand retrieved from TTLIS. It should be remarked that, in this research, words 'master student(s)', 'researcher(s)', and 'author(s)' refer to participants in this research.

\subsection{The first stage}

Systematic literature review is used to search for inclusive information with eradicating bias and document comprehensive information for a focused topic (Okoli \& Schabram, 2010). It aims to identify, appraise, and synthesise all empirical evidences that meet pre-specified eligibility criteria to answer given research questions (The Cochrane Library, 2013). There are five steps of systematic literature review (Kunz, Kleijnen, \& Antes, 2003; Centre for Reviews and Dissemination, 2009); 1) framing questions for a review, 2) identify relevant work, 3 ) assessing the quality of studied, 4) summarizing the evidence, and 5) interpreting the findings. This research started with the first step by framing the question; what is the nature of research directions in interior architecture in the higher education in Thailand. After framing the question, the search for relevant thesis documents and where to find them were defined. In this research, the main database used to search for 'the studied theses' was ThaiLIS-Thai Library Integrated System (TTLIS), where all research, theses, and dissertations in Thailand were systematically collected. The search for studied thesis documents in TTLIS database focused on master degree thesis documents. The term 'interior architecture' was used for 'subject search' to limit the search only for documents in interior architecture discipline, and the publication timeframe was limited between 1997 to 2016 .

\subsubsection{The first stage analytical process}

All 196 thesis documents obtained for TTLIS were profoundly reviewed and categorized into different types of research; exploratory research, descriptive research, analytical research, predictive research (Neville, 2005; Gray, 2004). Exploratory research looks for patterns, hypotheses, or ideas that can be tested and can generate basic theoretical framework for future research. Techniques for this type of research are working on case-studies, observations, and reviews of previous related studies, 2) descriptive research is used to identify and classify characters and elements of research subject. Quantitative techniques are often used for this type of research, 3) analytical research mainly tries to suggest or explain 'why' and 'how' some phenomena happen. The aim of analytical research is to identify different factors of such phenomena, and 4) predictive research is to speculate future possibilities of such phenomena relying on available evidence (Neville, 2005). In the analytical process of this stage, definitions and concepts of different research types were adopted as analytical framework. All 196 studied thesis documents were analysed with this framework one-by-one. The findings of this stage were concluded and presented with quantitative approach. Figure 1 is an excerpt of analytical table of systematic literature review in the first stage. 


\begin{tabular}{|c|c|c|c|c|c|c|c|c|c|c|c|}
\hline \multirow[t]{2}{*}{ Article No. } & \multicolumn{4}{|c|}{ Types of research } & \multicolumn{6}{|c|}{ Research approach } & \multirow[t]{2}{*}{ Memo } \\
\hline & Exploratory & Descriptive & Analytical & Predictive & Quantitative & Qualitative & Basic & Applied & Deductive & Inductive & \\
\hline 0.0 & & & $\begin{array}{l}\text { Study tactors } \\
\text { influensing conffict }\end{array}$ & & $\begin{array}{l}\text { Veriffing factors } \\
\text { retrieved from IIterature } \\
\text { review }\end{array}$ & & & & Decuutive approach & & \\
\hline 1 & & & $\begin{array}{l}\text { Comparing two } \\
\text { dififerent methods }\end{array}$ & & $\begin{array}{l}\text { Testing program b/ } \\
\text { comparing CRP and } \\
\text { resal messurement }\end{array}$ & & & & & & \\
\hline 2 & $\begin{array}{l}\text { Exploring then and } \\
\text { now condition of } \\
\text { intercor space }\end{array}$ & & & & & Surveying & & & & & \\
\hline 3 & $\begin{array}{l}\text { Exploirgt the existing } \\
\text { condition of traditional } \\
\text { housing }\end{array}$ & & & & & Surveying & & & & & \\
\hline 3.1 & & & $\begin{array}{l}\text { Studying influenoe } \\
\text { of organization } \\
\text { pollo/ on Interior } \\
\text { environmental } \\
\text { planning }\end{array}$ & & Interviewing & $\begin{array}{l}\text { Surveying existing } \\
\text { conditions }\end{array}$ & & & & & \\
\hline 3.2 & $\begin{array}{l}\text { Estimating existing } \\
\text { oonditions of } \\
\text { surrounding } \\
\text { environment }\end{array}$ & & & & Questionnaires & Photo-surveying & & & & & \\
\hline 3.3 & Testing sortivare & & & & & & & $\begin{array}{l}\text { Appying sotware in } \\
\text { a siluation }\end{array}$ & & & \\
\hline 3.4 & $\begin{array}{l}\text { Exploirng existing } \\
\text { conditions, problems, } \\
\text { and needs of small } \\
\text { ofice }\end{array}$ & & & & Questionnaires & & & & & $\begin{array}{l}\text { Gatnerng } \\
\text { iniomation from } \\
\text { participants }\end{array}$ & \\
\hline 3.5 & $\begin{array}{l}\text { Exploing nature of } 3^{t} \\
\text { place in the university }\end{array}$ & & & & \begin{tabular}{l|} 
Sureving physical \\
features of place. \\
Rating piyslasal features \\
of the place.
\end{tabular} & & & & $\begin{array}{l}\text { Referring the finding } \\
\text { to existing theory }\end{array}$ & & \\
\hline
\end{tabular}

Figure 1. An excerpt of analytical table of systematic literature review in the first stage

\subsection{The second stage}

Although systematic literature review can reveal the overview of research directions, but the analysis relied on a researcher individual attitude, background knowledge, and experience (Gray, 2004). In this stage, semi-structure interview was adopted to inquire authors of studied these. This method can unveil participants' subjective information; individual's experiences, attitudes, and opinions. The key success of this method are clarity and simplicity of the question (Knowles \& Condon, 1999). This stage aimed to explore deeply what did participants experience when they were working on the thesis in the master degree. The set of interview questions comprised three questions as follows; 1) could you please tell me your experiences of doing your thesis? 2) what were important events, issues, or ideas that encourage you to do your thesis? 3) would you like to add more comments about doing your thesis? Three guiding questions were gradually added into the interview. During the interview, these questions were used as the guideline to bring about the fluency of interview conversation. Thus, questions were unnecessarily asked in order, and these three questions may not be asked to every participant. This depended on the manner of the interview conversation. Participants could freely give their answers and opinions. The second stage began with making contacts with participants (authors of studied theses). They were contacted via their contact information, mainly emails. They were informed a brief of the research aim and asked if they agree to participate this research. Forty-two authors of studied theses replied and agreed to participate this research. The participants were given a call for the interview. The interview conversation took approximately 15-20 minutes for each participant. At the beginning of the conversation, each participant was asked for their permission to record the interview conversation. The interview comprised two parts. In the first part, individual's' general information, including gender, age, occupation, year of graduation, and thesis title were collected. In the second part, the interview conversation focused on asking participants with three guiding questions. Interview conversations were recorded with the audio recording device. Interview conversation record files were kept safely with encryption. Then, recorded conversations were transcribed word-by-word and placed into the analytical table. An excerpt from analytical tables is illustrated in Figure 2.

\subsubsection{The second stage analytical process}

Interpretative Phenomenological Analysis (IPA) was adopted for the second stage analytical method. With IPA, it is believed that all data retrieved from participants can reveal something of participants' sense making in relation to a phenomenon (Smith, Flowers, \& Larkin, 2009). Methodologically, IPA is relied on hermeneutic phenomenology and theories of interpretation (Smith \& Osborn, 2008). IPA is used to discover how people make sense of their world (Smith \& Osborn, 2008; Pringle, Drummond, McLafferty \& Hendry, 2011). IPA is a 
dynamic approach in which researchers actively connect with but do not intervene with the participants' world. That is, the two-stage interpretation (or double hermeneutic) process is adopted (Smith \& Osborn, 2008; Pringle, et al, 2011). In simple words, while participants are making sense of the experience, the researchers are trying to make sense of participants' trying to make sense of their experiences (Smith \& Osborn, 2008). In this stage, studied phenomenon were participants' experiences when they were doing their theses in the higher education level. IPA aims to retrieve rich data and subject it to detailed analysis case-by-case. With such a focused thorough process, it is considered reasonable to have a small participant pool (Smith \& Osborn, 2008). Small group of participants can constitute a reasonable sample in IPA if the pool is of a homogeneous nature. Data collection in IPA focuses on data that are likely to elicit detailed experience. In the analytical process, recorded conversations were transcribed word-by-word and placed into the analytical table shown in Figure 2 . The first column indicates number of participants. IPA analysis began with reading through original interview transcriptions shown in 2nd column word-by-word and sentence-to-sentence to get familiar with interview contents. In 3rd column, short notes and keywords in the initial interpretation were generated. Then, more abstract levels were developed in the secondary interpretation in the 4th column. In the 5th column, more abstract concepts were developed in keyword column. Themes were eventually developed with the highest abstract level in the 6th column. In the next step, themes retrieved from each participant were examined, looking for similarities, contrasts, and linkages across different participants, to generate super-ordinate themes. The last column is memo column. Memo is used to add remarkable issues and ideas.

\begin{tabular}{|c|c|c|c|c|c|c|}
\hline $\begin{array}{l}\text { Participant } \\
\text { No. }\end{array}$ & Original Transcription & Initial Interpretation & Secondary Interpretation & Keywords & Themes & Memo \\
\hline 01 & 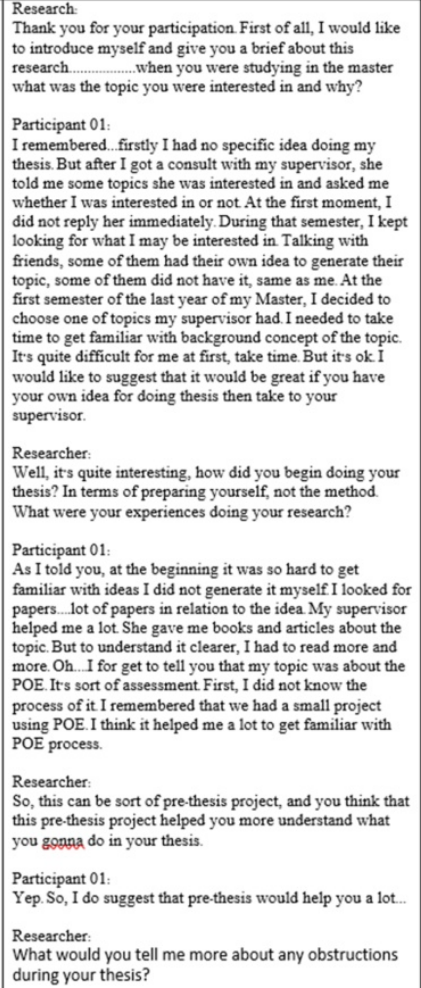 & $\begin{array}{l}\text { No pre-concept for thesis topic } \\
\text { Pre-concept from supervisor } \\
\text { Looking for idea of doing thesis } \\
\text { Students had no pre-concept for } \\
\text { thesis topic. } \\
\text { Turn to choose one of } \\
\text { supervisors pre-concept ideas. } \\
\text { Difficult to adopt others pre- } \\
\text { concept ideas. } \\
\text { Need of pre-concept of doing } \\
\text { thesis before beginning Master } \\
\text { degree. }\end{array}$ & $\begin{array}{l}\text { The problem of having no thesis } \\
\text { topic before studying Master } \\
\text { degree. } \\
\text { Important of supervision from } \\
\text { supervisor. } \\
\text { The problem of having no thesis } \\
\text { topic before studying Master } \\
\text { degree. } \\
\text { Good for studying new things, } \\
\text { but difficult and taking time. } \\
\text { Preparation before starting } \\
\text { Master Degree is needed. }\end{array}$ & $\begin{array}{l}\text { Important of self.preparation } \\
\text { before Master Degree. } \\
\text { Good points for supervisors } \\
\text { supervision. } \\
\text { Lack of students starting idea } \\
\text { Influences and help from } \\
\text { supervisor. } \\
\text { Study new thing during }\end{array}$ & $\begin{array}{l}\text { Self.preparation in } \\
\text { Pre-stage in Master } \\
\text { degree. } \\
\text { Supervisors } \\
\text { influences. }\end{array}$ & $\begin{array}{l}\text { Self.preparation } \\
\text { stage }\end{array}$ \\
\hline
\end{tabular}

Figure 2. An excerpt of the analytical table from interview transcriptions with IPA analytical method

\section{Results}

\subsection{The first stage results}

One hundred and ninety-six thesis documents were found in TTLIS database. Figure 3 shows thesis documents published in different years. Thesis documents had been rising in the first five years, and it reached the first highest point with 22 thesis documents in 2003. Afterward, thesis documents had been continuously decreasing until 2011. The publication reached the highest number again with 26 thesis documents in 2013. 


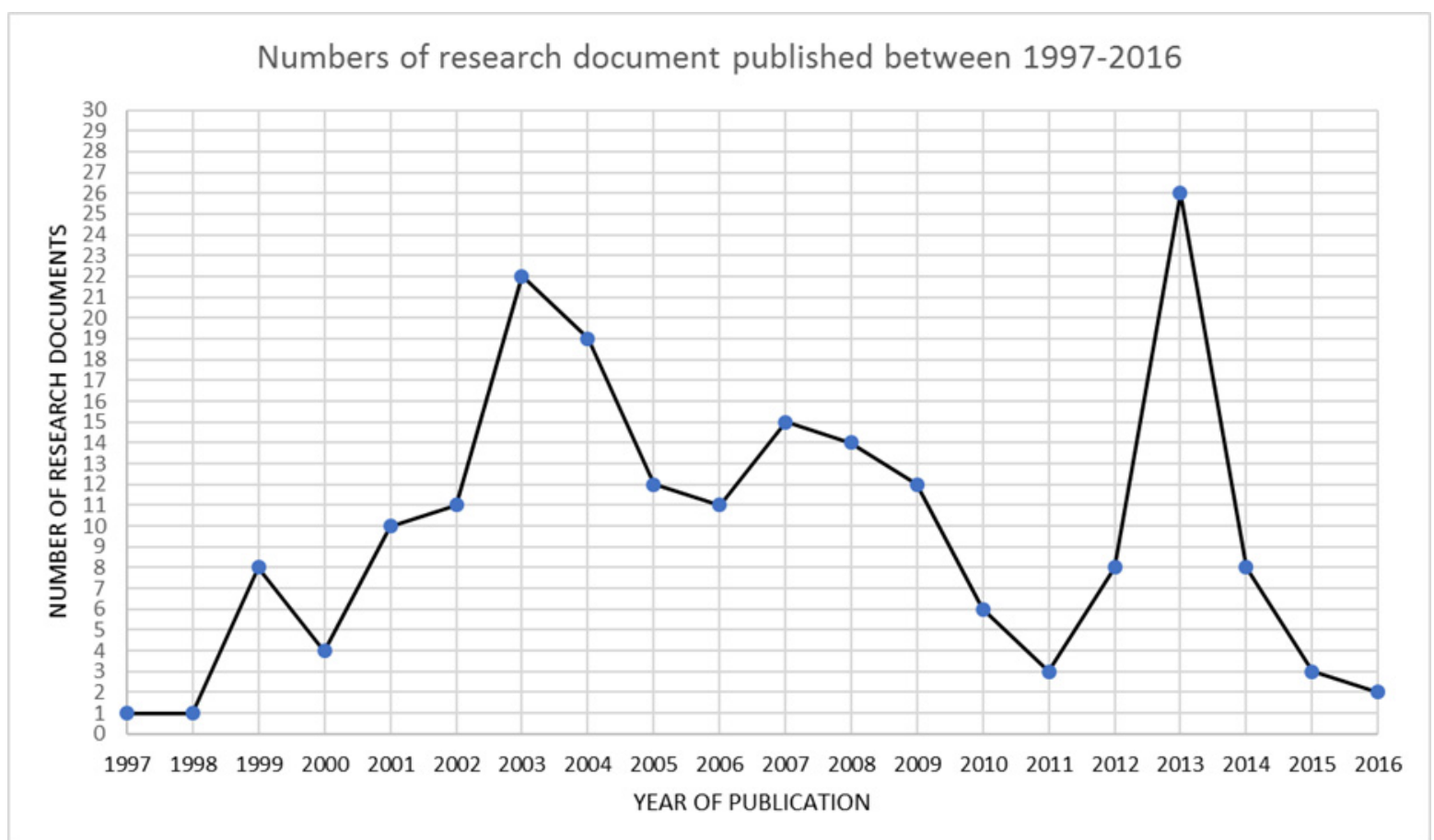

Figure 3. The number of interior architecture theses in the higher education found in TTLIS database between 1997 to 2016

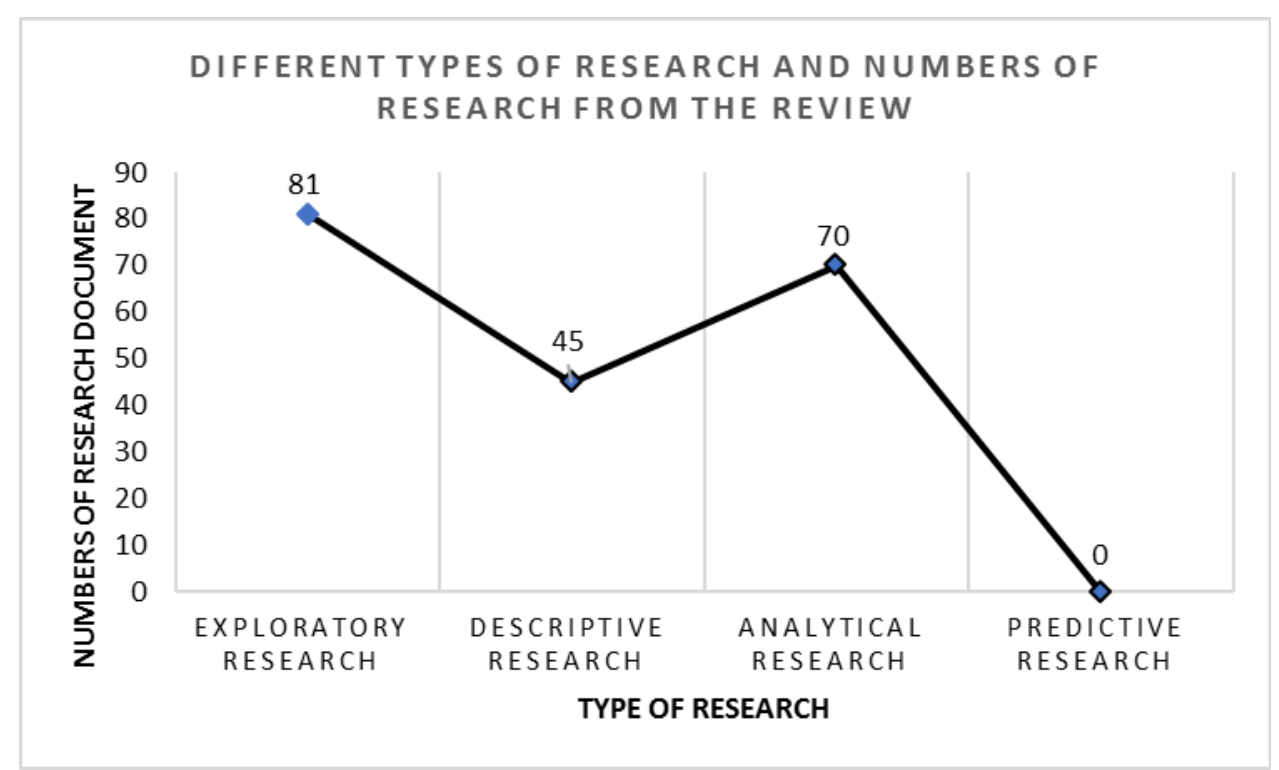

Figure 4. Different types of research in interior architecture in the higher education in Thailand between $1997-2016$

Figure 4 illustrates different types of research found in the systematic literature review. Exploratory research type shows the highest number of thesis documents with 81 publications. Analytical research type is in the second rank with 70 publications. Descriptive research type is in the third rank with 45 publications. The review shows that there was no predictive research type in interior architecture in the higher education in Thailand within recent two decades.

\subsection{The second stage results}

In the second stage, Interpretative Phenomenological Analysis (IPA) can conduce to more abstract levels, generate themes for each participant, and build up super-ordinate themes from cross-analysis among participants' 
interview data. With IPA, super-ordinate themes can reflect participants' experiences of doing theses and reveal research directions in interior architecture in the higher education level in Thailand. With the first guiding question; 'could you please tell me your experiences of doing your thesis', super-ordinate themes reflected three stages of doing thesis; 1) a stage before doing thesis, 2) a stage of getting ready to do thesis, and 3) a stage while doing thesis. The other two questions; 'what were important events, issues, or ideas that encourage you to do your thesis' and 'would you like to add other comments about doing your thesis', resulted in details of what happen in each stage of doing thesis. More discussions of super-ordinate themes are in the next section as follows:

\subsection{1 (be) Ready}

This is the stage before the participants begin doing thesis. In this stage, ideas of doing thesis can be conveyed to two different directions. The direction of thesis precisely relies on how research ideas came from in this stage. Firstly, thesis direction is determined by participant's original ideas; On-my-own. On the other hand, thesis direction is mainly influenced by participant's supervisor; On-others. Thesis initial ideas can be developed progressively if they are originated by participants themselves. Personal interests can encourage participants to conduct their theses and develop knowledges and skills effectively. On the other hand, a lack of participant's original ideas can convey to a lack of the intention and the passion for doing thesis.

\subsection{2 (up) Set (up)}

This is the stage that participants need to get themselves ready for doing their theses. This stage is in the middle of making decisions, searching among potential thesis topics, and learning methods. Two situations can possibly happen in this stage; 1) Set (up) and 2) (up) Set. Participants mentioned that initially they had a difficulty to understand research ideas obtained from their supervisors. In this case, thesis directions are precisely influenced by the supervisor. Thesis directions are over influenced by supervisors' ideas.

\subsubsection{Go (ne)}

In this stage, participants must start doing their theses because of the limited timeline. Possible situations in this stage are consequences of two prior stages, and it can convey to two endings. 'Go' is the situation that participants were doing thesis with full of individuals' interests, enthusiasms, and passions while 'Gone' is the situation that participants are doing theses with a lack of individuals' interests, enthusiasms, and passions.

\section{Discussion}

Research in interior architecture in the higher education in Thailand have been continuously conducted for two decades. In this article, research directions in interior architecture in the higher education in Thailand were explored through systematic literature review and in depth-interview with authors of the studied thesis documents. In the first stage, systematic literature review revealed overview of directions of studied thesis documents. Three main research types; 1) exploratory research, 2) descriptive research, and 3) analytical research, were discovered as three main research types studied thesis documents in interior architecture published from 1997 to 2016 in TTLIS. It is interesting that within recent two decades there have been no predictive research conducted in interior architecture in the higher education in Thailand. Among studied thesis documents, one of interesting research approaches found in the review was design prototype research. The finding of design prototype research is expected to be applied as the guidelines for future designs in interior architecture. The thesis of design prototypes and design criteria showed a larger number than other research types (81 of 196 thesis documents). From systematic literature review, design prototypes research relied on inductive approach, studying and exploring existing evidences or phenomenon from case studies of specific type(s) of interior architecture. Patterns, evidences, problems, and ideas obtained from case studies were analysed by comparing cases-by-cases to find co-pattern and co-phenomenon and generate prototypes or criteria for specific interior architecture. Examples of this research types are thesis topics as follows; 1) design criteria for Thai government's protectory for boys, 2) design prototype for Thai government pawnshop, and 3) design criteria of the house for independent wheelchair user in Bangkok.

Another interesting group of research types found in the systematic literature review was the research documenting existing conditions and features of physical, culture, and sociological contexts in relation to interior architecture. This research type mainly focuses on the study of unique spatial feathers and contents in the interior architectural of the selected buildings. For example, there are research studying and documenting existing conditions of interior spaces of Thai heritage buildings, such as temples, churches, and mosques. The research that study unique identity of the specific organization can be also considered as exploratory research type. This type of research begins with an exploration of organization identity. Then, unique identities are interpreted and 
transferred into design concept for the specific organization. There were numbers of remarkable research that explain influences, linkages, and relationships of studied factors, such as interior architecture features and people behaviours. This type of research can be categorized as the analytical research type. Mostly, the main purpose of analytical research found in the systematic literature review is to explain 'why' or 'how' things happen within interior architecture contexts and influence other things within interior architecture contexts. This type of research includes testing hypothesis within theoretical framework. Making a clarification on relationship between conceptual variables and operational variables is the key success of this type of research.

In the second stage, although the initial aim of the second stage was to explore general directions of research in interior architecture in the higher education in Thailand, but IPA analysis revealed profound understandings in terms of what influence research directions in both direct and indirect ways and what do participants really experience during doing theses or research. The three super-ordinate themes sequentially link together in the extent that a positive ending in a prior stage can bring about positive beginning in a following stage. (be)Ready is the stage before begin doing thesis or research. The direction of the thesis or research can convey to two different ways; 1) on-my-own and 2) on-others. (up) Set (up) is the stage that participants need to prepare themselves and get ready for doing thesis or research. While (up)Set refers to the situation that participants are encountering difficulties, Set (up) refers to positive experiences of self-preparation. Go (en) is the stage that participants are forced by limited timeframe to do thesis or research. The direction of the thesis or research can end up with two different ways; Go refers to the situation that participants are doing their theses with such positive forces as individuals' interests, enthusiasms, and passions, but Gone refers to the situation in the opposite way.

\section{Conclusion}

This article presents the exploration of research directions in interior architecture in the higher education in Thailand from 1997 to 2016. This research consisted of two stages. In the first stage, systematic literature review was adopted to explore thesis and research documents in interior architecture in the higher education in Thailand in ThaiLIS-Thai Library Integrated System (TTLIS) database. The findings of the first stage revealed research directions through objective points of view; categorising studied thesis documents according to types of research. Secondly, semi-structure interview with participants (the authors of studied thesis documents) revealed research directions through subjective points of view; experiences of doing master degree thesis through participants' individual experiences.

\section{References}

Centre for reviews and dissemination. (2009). Systematic reviews. York: University of York. Retrieved from https://www.york.ac.uk/media/crd/Systematic_Reviews.pdf

Connecticut. (2006). A guide to curriculum development-purposes, practices, procedures. Hartford: Connecticut State Dept. of Education, Division of Teaching and Learning, Bureau of Curriculum and Instruction.

Cooper, H., Hedges, L., \& Valentine, J. (Eds.). (2009). Handbook of Research Synthesis and Meta-Analysis, The. Russell Sage Foundation. Retrieved from http://www.jstor.org/stable/10.7758/9781610441384

Gray, E. D. (2004). Doing research in the real world. London: SAGA Publication.

Kawser, A. M. (2014). Curriculum development in Higher Education (Unpublished Master's thesis). University of Oslo, Norway.

Khan, S. K., Kunz, R., Kleijnen, J., \& Antes, G. (2003). Five steps to conducting a systematic review. Journal of the royal society of medicine, 96, 118-121. https://doi.org/10.1258/jrsm.96.3.118

Khan, A. M., \& Law, S. L. (2015). An integrative approach to curriculum development in higher education in USA: a theoretical framework. International Education Studies, 8(3), 66-76. http://dx.doi.org/10.5539/ies.v8n3p66

Knowles, E. S., \& Condon, C. A. (1999). Why people say 'yes': a dual process theory of acquiescence. Journal of Personality and Social Psychology, 77, 379-386. In Krueger (Eds.), Handbook of research methods in personality psychology (pp. 224-239). New York: Guilford. http://dx.doi.org/10.1037/0022-3514.77.2.379

Lattuca, L., \& Stark, J. (2009). Shaping the college curriculum. Academic Plans in Context (2nd ed.). San Francisco: Jossey-Bass. Retrived from https://leseprobe.buch.de/images-adb/f0/db/f0dba091-2926-4dce-b70e-5fb24a5ad8ce.pdf

Neville, C. (2005). Introduction to research and research methods. Effective Learning Service, Bradford University. 
Nielsen, D., Ieromonachou, P., Lin, P., \& White, A. (2015). Revision of curricula in higher education service provision: For better learning engagement and collaborative learning. Procedia Manufacturing, 3, 3583-3590. DOI: 10.1016/j.promfg.2015.07.723

Office of the Higher Education Commission. (2009). The framework of Thai Higher Education Standard 2009. Retrieved from http:/www.mua.go.th/users/tqfhed/news/FilesNews/FilesNews3/News328072552.pdf

Okoli, C., \& Schabram, K. (2010). A guide to conducting a systematic literature review of information systems research. Sprouts: Working Papers on Information System, 10(26), 879-910. DOI: 10.2139/ssrn.1954824

Paulhus, L. D., \& Vazire, S. (2007). The self-report method. In Robins, R. W., Fraley, C. R., \& Krueger F. R. (Eds.), Handbook of research methods in personality psychology (pp. 224-239). New York: Guilford. DOI: 10.1111/j.1744-6570.2008.01133_6.x

Pringle, J., Drummond, J., McLafferty, E., \& Hendry, C. (2011). Interpretative phenomenological analysis: A discussion and critique. Nurse Researcher, 18(3), 20. DOI: 10.7748/nr2011.04.18.3.20.c8459

Smith, J. A., \& Osborn, M. (2008). Chapter four: Interpretative Phenomenological Analysis. In J. A. Smith (Ed.), Qualitative psychology: A practical guide to research methods. Los Angeles: SAGE Publications Ltd. http://dx.doi.org/10.4135/9781446217870.n14

Smith, A. J., Flowers, P., \& Larkin, M. (2009). Interpretative phenomenological analysis. London, UK: SAGE Publications Ltd. http://dx.doi.org/10.1080/14780880903340091

\section{Copyrights}

Copyright for this article is retained by the author(s), with first publication rights granted to the journal.

This is an open-access article distributed under the terms and conditions of the Creative Commons Attribution license (http://creativecommons.org/licenses/by/4.0/). 